\title{
The relationship between food insecurity and overweight/obesity differs by birthplace and length of US residence
}

\author{
Suzanne Ryan-lbarra ${ }^{1, *}$, Emma $\bigvee$ Sanchez-Vaznaugh ${ }^{2}$, Cindy Leung ${ }^{3}$ and Marta Induni ${ }^{1,4}$ \\ ${ }^{1}$ Survey Research Group, Public Health Institute, 1825 Bell Street, Suite 102, Sacramento, CA 95825, USA: ${ }^{2}$ Health \\ Education Department, San Francisco State University, San Francisco, CA, USA: ${ }^{3}$ Center for Health and Community, \\ University of California, San Francisco, San Francisco, CA, USA: ${ }^{4}$ Cancer Registry of Greater California, Public \\ Health Institute, Sacramento, CA, USA
}

Submitted 13 May 2016: Final revision received 7 September 2016: Accepted 14 September 2016: First published online 28 November 2016

\begin{abstract}
Objective: To examine whether the cross-sectional association between food insecurity and overweight/obesity varied according to birthplace and length of residence in the USA among California women.

Design: Using cross-sectional, population-based data from the California Women's Health Survey (CWHS) 2009-2012, we examined whether the association between food insecurity and overweight or obesity varied by birthplace-length of US residence.

Setting: California, USA.

Subjects: Women ( $n$ 16008) aged 18 years or older.

Results: Among US-born women, very low food security (prevalence ratio $(P R)=1 \cdot 21 ; 95 \%$ CI $1 \cdot 11,1 \cdot 31)$ and low food security $(P R=1 \cdot 19 ; 95 \%$ CI $1 \cdot 10$, 1.28) were significantly associated with higher prevalence of overweight/obesity, after controlling for age, marital status, race/ethnicity, poverty and education. Among immigrant women who lived in the USA for 10 years or longer, very low food security was significantly associated with higher prevalence of overweight/ obesity, after controlling for covariates ( $\mathrm{PR}=1 \cdot 16$; 95\% CI 1.07, 1.27). Among immigrant women who had lived in the USA for less than 10 years, low and very low food security were not significantly associated with overweight/obesity, after controlling for covariates.

Conclusions: Food insecurity may be an important pathway through which weight may increase with longer US residence among immigrant women. Public health programmes and policies should focus on increasing food security for all women, including immigrant women, as one strategy to reduce the prevalence of overweight/obesity.
\end{abstract}

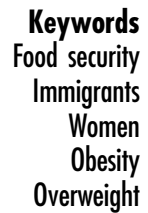

Several studies in the USA have found that food insecurity is significantly associated with higher BMI and greater risk of obesity among women overall ${ }^{(1-3)}$ and for specific subgroups such as Latina women ${ }^{(4,5)}$. However, little is known about the association between food insecurity and BMI among immigrant women or the role of length of residence in the USA on this relationship. Evidence suggests that although BMI is lower among immigrants compared with US natives ${ }^{(6)}$, BMI increases with longer US residence ${ }^{(7-11)}$ particularly among women ${ }^{(11)}$.

Immigrants tend to come to the USA from developing countries undergoing epidemiological and nutrition transitions. In these countries, the prevalence of obesity is increasing $^{(12,13)}$ and food insecurity is generally higher than in the USA ${ }^{(14)}$. Processed, energy-dense foods have been typically less available in developing countries than in developed countries, although this is changing with the increasing distribution of processed foods around the globe ${ }^{(14)}$. Even though immigrant women may have experienced food insecurity in their countries of origin, longer residence in host societies may increase exposure to energy-dense diets as well as vulnerability to higher BMI, overweight and obesity. Thus, although immigrant women may have lower average BMI than their US-born counterparts, over time, immigrant BMI patterns may mirror those of social groups in their host societies.

Initially, nativity outside the USA and dietary norms in countries of origin may act as protective factors against higher BMI among US immigrants. With longer residence in host societies, changes in fruit and vegetable 
consumption $^{(15,16)}$ and lack of access to healthy foods in poor neighbourhoods ${ }^{(17-20)}$ where low-income immigrants are more likely to live may increase food insecurity and lead to higher BMI and overweight/obesity among immigrants. Thus, we might expect food insecurity to be associated with higher rates of overweight and obesity among immigrant women with longer US stays, as compared with immigrants with shorter US stays.

To inform current and future interventions to prevent obesity and improve health among all women, research is needed to disentangle the role of both food insecurity and length of residence in the variation of obesity among US-born and foreign-born women. To strengthen knowledge about the roles of food insecurity and length of residence in the epidemiology of obesity among US immigrant women compared with native women, we utilized a large sample of women in California to investigate whether the association between food insecurity and overweight/obesity varied according to birthplace and length of residence.

\section{Methods}

\section{Participants}

We used four years of data from the California Women's Health Survey (CWHS) 2009-2012. CWHS is an annual, cross-sectional, population-based telephone survey of non-institutionalized households, and methods have been described elsewhere ${ }^{(21)}$. Briefly, using random digit dialling, one woman aged 18 years or older per household was randomly selected to participate in a telephone interview. Respondents were interviewed in English and Spanish. CWHS data are weighted to account for the complex sampling design and adjust for non-response and households without telephones. In the combined four years, there were a total of 18930 respondents. After excluding pregnant women ( $n$ 235), those with implausible ( $>65$ or $<10 \mathrm{~kg} / \mathrm{m}^{2}$ ) or missing BMI values ( $n$ 2385) and respondents missing information on food insecurity ( $n$ 51) or birthplace/length of residence ( $n$ 251), our analytic sample included 16008 women. Women with missing BMI values refused to provide either weight and/or height, usually because the respondents did not complete the entire survey (partial completes).

\section{Weight status}

BMI was calculated as self-reported weight in kilograms divided by the square of self-reported height in metres. Obesity, overweight and normal weight were defined using standard cut-off points: $\mathrm{BMI} \geq 30 \cdot 0 \mathrm{~kg} / \mathrm{m}^{2}$ as obese, $\mathrm{BMI}=$ $25.0-29.9 \mathrm{~kg} / \mathrm{m}^{2}$ as overweight and $\mathrm{BMI}=18.5-24.9 \mathrm{~kg} / \mathrm{m}^{2}$ as normal weight. Women who were underweight (BMI $<18.5 \mathrm{~kg} / \mathrm{m}^{2}$ ) comprised $2.6 \%$ of the total weighted sample ( $n$ 328) and were excluded from all analyses due to small sample size (cells with ten or fewer observations) when compared by food security status and birthplace-length of residence.

\section{Food security}

Food security was assessed using the six-item short form of the US Household Food Security Module, developed and validated by the US Department of Agriculture ${ }^{(22)}$. Each question in the six-item short-form module was scored following the US Department of Agriculture protocol. The scores for each question were summed to create a food security score for each participant. Women were classified using the US Department of Agriculture guidelines as follows: food secure (raw score $=0-1$ ), low food security (raw score $=2-4$ ) or very low food security (raw score $=5-6)^{(23)}$. Food insecurity refers to both low and very low food security categories.

\section{Birthplace-length of residence}

Birthplace and length of residence were combined into one single variable with three categories: (i) US-born; (ii) foreign-born living in the USA for 10 years or longer; and (iii) foreign-born living in the USA for less than 10 years. We used this 10-year threshold because prior research among immigrants has reported that BMI tends to increase after 10 years of US residence ${ }^{(9)}$.

\section{Covariates}

We used directed acyclic graphs to select covariates to include in multivariable models. Directed acyclic graphs are useful tools to select covariates that meet criteria as potential confounders ${ }^{(24,25)}$. We selected the following demographic and socio-economic factors: age centred at its mean; a quadratic term for age to assess potential non-linear age effects on overweight/obesity; self-reported race/ethnicity (white, African American/black, Hispanic/ Latina, Asian); marital status (married/living with partner, separated/divorced/widowed, never married); education (less than high school, high school or some college, college graduate or higher); and federal poverty level $(<185 \%$, $\geq 185 \%$ ). Food assistance (defined as participating in the Supplemental Nutrition Assistance Program (SNAP) or the Special Supplemental Nutrition Program for Women, Infants, and Children (WIC) in the past 12 months) and having children under 18 years old in the household were included as covariates in sensitivity analyses. Due to small sample size, we excluded 304 women who did not selfidentify with these four race/ethnicity categories: white, African American/black, Hispanic/Latina or Asian.

\section{Statistical analysis}

We compared average BMI and prevalence of normal weight, overweight and obesity along with distributions of other variables among women in each food security 
group. We used $\chi^{2}$ statistics for categorical variables and ANOVA for continuous variables to assess the statistical significance of observed differences.

Adjusted prevalence ratios (PR) of overweight/obesity and their 95\% confidence intervals were calculated using Cox proportional hazards models for complex surveys (PROC SURVEYPHREG) in the statistical software package SAS version 9.3. Due to small cell sizes for immigrants with less than 10 years of US residence, we combined overweight and obese categories to calculate PR and confidence intervals. To examine potential effect modification by birthplace-length of residence, a product term (food security and birthplace-length of residence) was included in Cox models using the overall sample. Because a Wald test for product terms is not calculated in PROC SURVEYPHREG, we used PROC SURVEYLOGISTIC to calculate the $P$ value for a Wald test for the product term. Because the $P$ value for the product term was $0 \cdot 1$, additional models were stratified by birthplace-length of residence.
SAS version 9.3 survey procedures were used for all analyses to adjust for the complex survey sampling design. The level of significance was defined as $P<0.05$ for all tests except for product terms.

\section{Results}

In the overall sample, $28 \%$ of women reported food insecurity ( $17 \%$ had low food security, and $11 \%$ had very low food security; Table 1). Food-insecure women were more likely to be immigrants; immigrants born in Mexico comprised the largest group (33.6\%) of all food-insecure women. Food-insecure women were also less likely to be married and to be more socio-economically disadvantaged than food-secure women.

Overall, the prevalence of obesity was highest among women with very low food security (43\%), and second highest among women with low food security (35\%; Table 2).

Table 1 Characteristics of the sample by food security status, California Women's Health Survey (CWHS) 2009-2012*†

\begin{tabular}{|c|c|c|c|c|c|c|}
\hline & \multicolumn{2}{|c|}{$\begin{array}{c}\text { Food secure } \\
\text { (n 12272; } 72.5 \%)\end{array}$} & \multicolumn{2}{|c|}{$\begin{array}{l}\text { Low food secure } \\
\text { (n 2288; 16.9\%) }\end{array}$} & \multicolumn{2}{|c|}{$\begin{array}{l}\text { Very low food secure } \\
\quad(n 1448 ; 10.6 \%)\end{array}$} \\
\hline & Mean or $n$ & $\begin{array}{c}\text { SE or } \\
\text { weighted \% }\end{array}$ & Mean or $n$ & $\begin{array}{c}\text { SE or } \\
\text { weighted \% }\end{array}$ & Mean or $n$ & $\begin{array}{c}\text { SE or } \\
\text { weighted \% }\end{array}$ \\
\hline Age (years), mean and SE & $47 \cdot 5$ & 0.26 & $42 \cdot 2$ & 0.46 & $43 \cdot 7$ & 0.50 \\
\hline \multicolumn{7}{|l|}{ Race/ethnicity } \\
\hline White & 9001 & $56 \cdot 8$ & 745 & $26 \cdot 6$ & 517 & $29 \cdot 7$ \\
\hline African American/black & 412 & $5 \cdot 3$ & 118 & $7 \cdot 0$ & 94 & $9 \cdot 7$ \\
\hline Hispanic/Latina & 2170 & $22 \cdot 0$ & 1347 & $57 \cdot 6$ & 814 & $56 \cdot 3$ \\
\hline Asian & 689 & $15 \cdot 8$ & 78 & $8 \cdot 8$ & 23 & $4 \cdot 3$ \\
\hline \multicolumn{7}{|l|}{ Marital status } \\
\hline Married & 8498 & 63.6 & 1388 & $56 \cdot 1$ & 741 & $50 \cdot 2$ \\
\hline Separated/divorced/widowed/living with partner & 2933 & $18 \cdot 3$ & 615 & $21 \cdot 1$ & 520 & 30.9 \\
\hline Never married & 996 & $18 \cdot 1$ & 283 & 22.9 & 187 & $18 \cdot 9$ \\
\hline \multicolumn{7}{|l|}{ Birthplace/US length of residence } \\
\hline US-born & 9902 & 74.5 & 1059 & $48 \cdot 3$ & 722 & $49 \cdot 7$ \\
\hline Foreign-born, $\geq 10$ years of residence in USA & 2095 & 21.9 & 1063 & $44 \cdot 2$ & 637 & $44 \cdot 7$ \\
\hline Foreign-born, $<10$ years of residence in USA & 226 & 3.6 & 131 & $7 \cdot 5$ & 72 & $5 \cdot 6$ \\
\hline \multicolumn{7}{|l|}{ Birth country or region $\ddagger$} \\
\hline Americas & 11173 & $85 \cdot 8$ & 2155 & $91 \cdot 3$ & 1373 & $94 \cdot 2$ \\
\hline USA & 9902 & $74 \cdot 3$ & 1059 & $47 \cdot 8$ & 722 & $49 \cdot 4$ \\
\hline Mexico & 895 & $8 \cdot 6$ & 922 & $36 \cdot 3$ & 541 & $36 \cdot 6$ \\
\hline Central America & 142 & $1 \cdot 3$ & 133 & 5.5 & 97 & 6.5 \\
\hline Canada & 114 & 0.7 & $\S$ & - & $\S$ & - \\
\hline South America & 88 & 0.7 & 27 & $1 \cdot 1$ & 13 & 0.8 \\
\hline Caribbean & 32 & 0.2 & 14 & 0.4 & $\S$ & - \\
\hline Western Pacific Region & 360 & $7 \cdot 1$ & 48 & $5 \cdot 2$ & 25 & 3.6 \\
\hline South-East Asian Region & 118 & $2 \cdot 7$ & 15 & $1 \cdot 2$ & $\S$ & - \\
\hline Europe Region & 480 & $3 \cdot 1$ & 32 & 1.0 & 23 & 1.4 \\
\hline Eastern Mediterranean Region & 87 & $1 \cdot 0$ & 14 & $1 \cdot 1$ & $\S$ & - \\
\hline African Region & 33 & 0.4 & $\S$ & - & $\S$ & - \\
\hline \multicolumn{7}{|l|}{ Education } \\
\hline$<$ High school & 865 & $7 \cdot 8$ & 910 & 35.8 & 608 & 39.7 \\
\hline High school or some college & 5674 & $47 \cdot 1$ & 1043 & $49 \cdot 1$ & 669 & $47 \cdot 6$ \\
\hline College or higher & 5724 & $45 \cdot 1$ & 333 & $15 \cdot 1$ & 169 & $12 \cdot 7$ \\
\hline \multicolumn{7}{|l|}{ Federal poverty level } \\
\hline$\leq 185 \%$ & 2332 & $27 \cdot 1$ & 1616 & $74 \cdot 6$ & 1163 & 83.5 \\
\hline$>185 \%$ & 8973 & 72.9 & 582 & 25.4 & 240 & $16 \cdot 5$ \\
\hline
\end{tabular}

${ }^{*}$ Chi-square tests of heterogeneity are statistically significant between food-secure, low food-secure and very low food-secure groups $(P<0.01)$. Percentages may not add to 100 due to rounding.

†All percentages and means corrected for the complex design of the CWHS using SAS survey procedures.

‡Defined using WHO epidemiological sub-regions.

$\S$ Not reported due to small cell sizes. 
Table 2 Unadjusted prevalence of overweight and obesity according to food insecurity, for the overall sample and by birthplace-US length of residence for women in California, California Women's Health Survey (CWHS) 2009-2012*

\begin{tabular}{|c|c|c|c|c|c|c|}
\hline & \multicolumn{2}{|c|}{ Obese } & \multicolumn{2}{|c|}{ Overweight } & \multicolumn{2}{|c|}{ Normal weight } \\
\hline & $n$ & $\%$ & $n$ & $\%$ & $n$ & $\%$ \\
\hline \multicolumn{7}{|l|}{ Overall } \\
\hline Food secure & 2477 & $20 \cdot 3$ & 3540 & $27 \cdot 9$ & 5987 & $51 \cdot 8$ \\
\hline Low food secure & 836 & 34.5 & 751 & $31 \cdot 1$ & 669 & 34.4 \\
\hline Very low food secure & 613 & 43.0 & 441 & 29.9 & 369 & $27 \cdot 1$ \\
\hline \multicolumn{7}{|c|}{ Foreign-born, $<10$ years in USA } \\
\hline Food secure & 34 & $12 \cdot 5$ & 70 & $30 \cdot 7$ & 114 & $56 \cdot 8$ \\
\hline Low food secure & 37 & $21 \cdot 8$ & 47 & 31.8 & 45 & $46 \cdot 4$ \\
\hline Very low food secure & 34 & $44 \cdot 1$ & 18 & $24 \cdot 2$ & 20 & 31.7 \\
\hline \multicolumn{7}{|c|}{ Foreign-born, $\geq 10$ years in USA } \\
\hline Food secure & 389 & $16 \cdot 2$ & 669 & $30 \cdot 8$ & 983 & $53 \cdot 1$ \\
\hline Low food secure & 385 & $32 \cdot 8$ & 396 & $36 \cdot 2$ & 277 & $31 \cdot 0$ \\
\hline Very low food secure & 267 & 41.7 & 231 & $35 \cdot 2$ & 130 & $23 \cdot 1$ \\
\hline \multicolumn{7}{|l|}{ US-born } \\
\hline Food secure & 2044 & $21 \cdot 8$ & 2783 & $27 \cdot 0$ & 4870 & $51 \cdot 2$ \\
\hline Low food secure & 402 & 38.3 & 296 & $26 \cdot 2$ & 336 & 35.5 \\
\hline Very low food secure & 304 & 44.0 & 186 & 25.9 & 216 & 30.1 \\
\hline
\end{tabular}

*All percentages corrected for the complex design of the CWHS using SAS survey procedures.

Table 3 Adjusted obesity/overweight prevalence ratios (PR) according to food insecurity, overall and by birthplace-US length of residence for women in California, California Women's Health Survey (CWHS) 2009-2012*

\begin{tabular}{|c|c|c|}
\hline & $\begin{array}{l}\mathrm{PR} \dagger \text { of obesity } \\
\text { and overweight }\end{array}$ & $95 \% \mathrm{Cl}$ \\
\hline \multicolumn{3}{|l|}{ Overall sample } \\
\hline Food secure & Reference & \\
\hline Low food secure & $1 \cdot 18$ & $1 \cdot 10,1 \cdot 27$ \\
\hline Very low food secure & 1.20 & $1.11,1.31$ \\
\hline \multicolumn{3}{|c|}{ Foreign-born, $<10$ years in USA } \\
\hline Food secure & Reference & \\
\hline Low food secure & 0.98 & $0.73,1.30$ \\
\hline Very low food secure & 1.02 & $0.77,1.36$ \\
\hline \multicolumn{3}{|c|}{ Foreign-born, $\geq 10$ years in USA } \\
\hline Food secure & Reference & \\
\hline Low food secure & 1.07 & $0.99,1.17$ \\
\hline Very low food secure & $1 \cdot 16$ & $1.07,1.27$ \\
\hline \multicolumn{3}{|l|}{ US-born } \\
\hline Food secure & Reference & \\
\hline Low food secure & 1.19 & $1 \cdot 10,1.28$ \\
\hline Very low food secure & 1.21 & $1.11,1.31$ \\
\hline
\end{tabular}

${ }^{*}$ All prevalence ratios and confidence intervals corrected for the complex design of the CWHS using SAS survey procedures.

†Prevalence ratios adjusted for age, age-squared, race/ethnicity, marital status, education, poverty and survey year. In the overall model, also adjusted for birthplace-length of residence and food security $\times$ birthplacelength of residence.

This pattern persisted among the US-born and immigrants with longer and shorter US stays. The prevalence of overweight was generally similar among low and very low food-secure women, for all groups except immigrants with US residence of less than 10 years, although their sample size was small.

In the overall sample, low and very low food security were positively associated with overweight/obesity, compared with food-secure women, adjusting for age, agesquared, race/ethnicity, marital status, education, poverty and birthplace-length of residence (Table 3).
PR stratified by birthplace-length of residence and adjusted for age, age-squared, race/ethnicity, marital status, education and poverty are presented here. Among USborn women, very low food security $(\mathrm{PR}=1 \cdot 21$; $95 \% \mathrm{CI}$ $1 \cdot 11,1 \cdot 31)$ and low food security $(\mathrm{PR}=1 \cdot 19 ; 95 \%$ CI $1 \cdot 10$, $1 \cdot 28)$ were significantly associated with overweight/obesity compared with food-secure women. Among immigrant women with 10 or more years of US residence, relative to food-secure women, very low food security was significantly associated with greater likelihood of overweight/obesity ( $\mathrm{PR}=1.16$; 95\% CI 1.07, 1.27); low food security was positively associated with overweight/obesity, but the confidence interval included the null ( $\mathrm{PR}=$ 1.07; $95 \%$ CI 0.99, 1.17). Among immigrant women with less than 10 years of US residence, neither very low food security ( $\mathrm{PR}=1.02 ; 95 \%$ CI $0.77,1.36$ ) nor low food security ( $\mathrm{PR}=0.98 ; 95 \% \mathrm{CI} 0.73,1.30)$ was significantly associated with overweight/obesity. In sensitivity analyses adjusting for food assistance (SNAP or WIC) and children under 18 years old in the household, PR were similar to those reported above.

\section{Discussion}

In a large representative sample of women in California, we found that food insecurity was associated with higher likelihood of overweight/obesity among US-born women and immigrant women with longer US stays, after adjustment for sociodemographic factors. These results concur with other US studies using cross-sectional data which found that food insecurity was associated with higher BMI, overweight and obesity among women in California ${ }^{(1)}$ and Latina women ${ }^{(4,5)}$. Similarly, using measured weight and height, one longitudinal study found that food insecurity was significantly associated with weight gain in a large representative sample of women in the USA ${ }^{(3)}$. 
Our study builds upon this literature by investigating whether the association between food insecurity and weight status varied according to birthplace-length of residence. We found that the association between food insecurity and weight status was more pronounced among immigrant women with longer residence in the USA than among immigrant women with shorter residence in the USA. Prior research has found that compared with men, women may be more susceptible to higher BMI with longer US residence ${ }^{(11)}$. Among women, food insecurity is associated with obesity in Mexico ${ }^{(26)}$, South $\mathrm{Korea}^{(27)}$ and some ethnic groups in Iran ${ }^{(28)}$. Food insecurity was associated with underweight, but not excess weight, among women in Colombia ${ }^{(29)}$.

Our study's findings suggest that food insecurity may be an important pathway that may influence susceptibility to overweight/obesity as immigrant women live longer in the USA. The experience of food insecurity combined with greater exposure to some features of a developed society may be underlying mechanisms that lead to higher BMI, overweight and obesity among immigrant women.

For example, in the USA, lower-quality diets rich in energy-dense but nutrient-poor foods, such as refined grains, ground beef and processed meats, are more likely to be consumed by people with lower socio-economic resources $^{(30)}$ and tend to be cheaper per kilojoule than diets high in nutrient-dense foods like fruits and vegetables $^{(31,32)}$. The high cost per kilojoule of fruits, vegetables and other healthy foods may be out of reach for low-income populations to purchase and consume regularly ${ }^{(31)}$. Limited availability of supermarkets in some poor and minority neighbourhoods (where immigrants of low socio-economic status are likely to live) may impede access to fruits, vegetables and other nutrient-rich foods ${ }^{(33)}$. Observational studies have found that access to supermarkets is associated with a healthier $\operatorname{diet}^{(33,34)}$. However, experimental studies with control groups have found that supermarket access is not significantly associated with diet or weight status ${ }^{(35-37)}$. Marketing incentives for low-cost, energy-dense foods are particularly damaging to groups of low socio-economic status ${ }^{(30)}$; this may in turn influence food-insecure immigrant women with longer US stays to replace healthier diets for energydense, nutrient-poor foods that represent a source of affordable energy. In contrast, recent immigrant women may escape the influence of such incentives, as they may hold on to purchasing behaviours from their countries of origin or because they may not be as exposed to heavy food advertising and marketing in the USA as the general population ${ }^{(38)}$. Nutrition education interventions may be less effective at increasing the consumption of healthy foods for those of low socio-economic status, compared with those of higher socio-economic status ${ }^{(39)}$.

The obesogenic environment in the USA may affect immigrants slowly over many years. Foreign nativity and norms in countries of origin may act as protective factors against higher BMI and may be more powerful than the influence of food insecurity alone. Some studies have found that immigrants from Mexico and Korea are more likely to consume fruits and vegetables than US natives ${ }^{(15,40,41)}$. A prior study found that Latino immigrants may rely on staples that are rich in fibre, such as beans and corn tortillas, and micronutrients, such as tomatoes, during periods of food insecurity ${ }^{(4)}$. These patterns could buffer against the harmful effects of food insecurity among immigrant women in their first few years of residence in the USA. However, with longer residence in the USA, immigrant women may begin to respond to food shortages in similar ways as their counterparts with longer US residence and women born in the USA; for example, they may decrease consumption of lower-energy-density foods rich in micronutrients and fibre, and replace them with cheaper, energy-dense, low-nutrient foods that are frequently consumed by those in socio-economically disadvantaged groups in the USA ${ }^{(30)}$.

Additionally, the observed food insecurity patterning in BMI by birthplace and length of residence may be due to factors closely linked to food insecurity such as psychosocial stress and biological functioning (e.g. allostatic load ${ }^{(42)}$. A prospective study found that experiencing psychosocial stress was associated with increased BMI over a 13-year follow-up period among black women ${ }^{(43)}$. Some evidence suggests that women with greater central fat have greater levels of cortisol secretion when experiencing stress ${ }^{(44)}$ and that experiencing chronic stress, as measured by allostatic load, may cause increased weight gain $^{(45)}$. This could explain the difference in our study's observed association between food insecurity and overweight/obesity among recent immigrant women $v$. those with longer US stays. During longer exposure to US culture and social norms, immigrant women may have had longer exposure to psychosocial stress associated with experiences of discrimination and integration into the new society $^{(46-49)}$, as well as stress related to prolonged food insecurity; recent immigrant women may not have had a sufficient dose of such stressors to manifest in higher BMI.

We were unable to assess the role of environmental and social factors that may influence the differential association between food insecurity and overweight/obesity by birthplace-length of residence because such data are not available in the $\mathrm{CWHS}^{(21)}$. Future research is needed to improve our understanding of this relationship and particularly explain why the association between food insecurity and overweight/obesity differs by birthplace-length of residence. Social programmes such as food assistance like SNAP and WIC may be important mediating factors of the relationship between food insecurity and overweight/ obesity. Future studies should examine the potential mediating role of food assistance programmes in the food insecurity-overweight/obesity association among native women as well as immigrant women with various lengths of residence in the USA. Future studies should also 
examine whether immigrant diet changes are differentially patterned by food insecurity status and whether these patterns explain the increased BMI with longer US residence. The relationship between food insecurity and risk of obesity has been found to differ by race/ethnicity, where the prevalence of obesity increased with increasing food insecurity for Asians, blacks and Hispanics, but not for non-Hispanic white women ${ }^{(1)}$. Additional research is needed to examine the interaction between food insecurity and birthplace and length of residence within racial/ ethnic groups. Finally, we could not examine the association between food insecurity and overweight/obesity according to country of origin due to small sample sizes; future studies should investigate these associations with samples disaggregated by country of origin.

The current study used cross-sectional data; thus, we are unable to make causal inferences. Self-reported height and weight were used to calculate BMI, which is highly correlated with technician-measured BMI among adults $^{(50)}$. However, because self-reported BMI has also been found to underestimate BMI and prevalence of overweight/obesity by age and race/ethnicity ${ }^{(51)}$, we controlled for these factors, so underestimation of BMI may have been minimized.

\section{Conclusions}

The present study provides evidence suggesting that the association between food insecurity and overweight/ obesity is more pronounced among immigrant women with longer US stays compared with recent immigrant women. Our findings imply that food insecurity combined with prolonged exposure to a developed society may increase vulnerability to higher BMI, overweight and obesity among immigrant women. Further investigations on the possible influences of food insecurity on stress, changes in diet and biological mechanisms underlying such differences are needed. To promote healthy weight among all women, programmes and policies should focus on reducing food insecurity and increasing access to healthy foods. Food assistance programmes should consider both birthplace and length of residence in their eligibility criteria and programme implementation. Overweight and obesity prevention programmes may be more effective at reducing overweight and obesity among women overall by addressing food insecurity among socio-economically disadvantaged women, including recent immigrant women.

\section{Acknowledgements}

Acknowledgements: The authors would like to recognize and thank the participants in the CWHS 2009-2012. This study would not have been possible without their valuable time and willingness to share personal information. Financial support: This research received no specific grant from any funding agency in the public, commercial or non-for-profit sectors. The authors acknowledge salary support by a grant from the National Heart, Lung, and Blood Institute of the National Institutes of Health (E.V.S.-V., grant number K01HL115471). The content is solely the responsibility of the authors and does not necessarily represent the official views of this institution. Conflict of interest: None. Authorship: S.R.-I. and E.V.S.-V. designed the study. S.R.-I. conducted analyses and wrote the first draft of the article. E.V.S.-V., C.L. and M.I. contributed to revisions and editing of the article. M.I. contributed to data collection. Ethics of buman subject participation: This study was conducted according to the guidelines laid down in the Declaration of Helsinki and all procedures involving human subjects/patients were approved by California's Health and Human Services Agency, Committee for the Protection of Human Subjects. Verbal informed consent was obtained from all subjects. Verbal consent was witnessed and formally recorded.

\section{References}

1. Adams EJ, Grummer-Strawn L \& Chavez G (2003) Food insecurity is associated with increased risk of obesity in California women. J Nutr 133, 1070-1074.

2. Hanson KL, Sobal J \& Frongillo EA (2007) Gender and marital status clarify associations between food insecurity and body weight. J Nutr 137, 1460-1465.

3. Wilde PE \& Peterman JN (2006) Individual weight change is associated with household food security status. J Nutr 136, 1395-1400.

4. Kaiser LL, Townsend MS, Melgar-Quiñonez HR et al. (2004) Choice of instrument influences relations between food insecurity and obesity in Latino women. Am J Clin Nutr 80, $1372-1378$.

5. Leung CW, Williams DR \& Villamor E (2012) Very low food security predicts obesity predominantly in California Hispanic men and women. Public Health Nutr 15, 2228-2236.

6. Bates LM, Acevedo-Garcia D, Alegría M et al. (2008) Immigration and generational trends in body mass index and obesity in the United States: results of the National Latino and Asian American Survey, 2002-2003. Am J Public Health 98, 70-77.

7. Antecol H \& Bedard K (2006) Unhealthy assimilation: why do immigrants converge to American health status levels? Demography $\mathbf{4 3}, 337-360$.

8. Barcenas CH, Wilkinson AV, Strom SS et al. (2007) Birthplace, years of residence in the United States, and obesity among Mexican-American adults. Obesity (Silver Spring) 15, 1043-1052.

9. Goel MS, McCarthy EP, Phillips RS et al. (2004) Obesity among US immigrant subgroups by duration of residence. JAMA 292, 2860-2867.

10. Lauderdale DS \& Rathouz PJ (2000) Body mass index in a US national sample of Asian Americans: effects of nativity, years since immigration and socioeconomic status. Int $\mathrm{J}$ Obes Relat Metab Disord 24, 1188-1194.

11. Sanchez-Vaznaugh EV, Kawachi I, Subramanian SV et al. (2008) Differential effect of birthplace and length of residence on body mass index (BMI) by education, gender and race/ethnicity. Soc Sci Med 67, 1300-1310. 
12. World Health Organization (2016) Obesity and overweight fact sheet. http://www.who.int/mediacentre/factsheets/ fs311/en/ (accessed October 2016).

13. Mendez MA, Monteiro CA \& Popkin BM (2005) Overweight exceeds underweight among women in most developing countries. Am J Clin Nutr 81, 714-721.

14. Food and Agriculture Organization of the United Nations, International Fund for Agricultural Development \& World Food Programme (2013) The State of Food Insecurity in the World 2013: The Multiple Dimensions of Food Security. Rome: FAO.

15. Bermúdez OI, Falcón LM \& Tucker KL (2000) Intake and food sources of macronutrients among older Hispanic adults: association with ethnicity, acculturation, and length of residence in the United States. J Am Diet Assoc 100, 665-673.

16. Yeh M-C, Ickes SB, Lowenstein LM et al. (2008) Understanding barriers and facilitators of fruit and vegetable consumption among a diverse multi-ethnic population in the USA. Health Promot Int 23, 42-51.

17. Inagami S, Cohen DA, Finch BK et al. (2006) You are where you shop: grocery store locations, weight, and neighborhoods. Am J Prev Med 31, 10-17.

18. Morland K, Diez Roux AV \& Wing S (2006) Supermarkets, other food stores, and obesity: the atherosclerosis risk in communities study. Am J Prev Med 30, 333-339.

19. Morland K, Wing S \& Diez Roux A (2002) The contextual effect of the local food environment on residents' diets: the atherosclerosis risk in communities study. Am J Public Health 92, 1761-1767.

20. Morland K, Wing S, Diez Roux A et al. (2002) Neighborhood characteristics associated with the location of food stores and food service places. Am J Prev Med 22, 23-29.

21. Induni M \& Hoegh H (2006) California Women's Health Survey methods. In Women's Health: Findings from the California Women's Health Survey, 1997-2003, pp. 1-1-1-4. Sacramento, CA: California Department of Health Services, Office of Women's Health.

22. Bickel G, Nord M, Price C et al. (2000) Guide to Measuring Household Food Security, Revised 2000. Alexandria, VA: US Department of Agriculture, Food and Nutrition Service.

23. US Department of Agriculture (2012) US Household Food Security Module: Six-Item Short Form. Washington, DC: US Department of Agriculture, Economic Research Service.

24. Greenland S, Pearl J \& Robins JM (1999) Causal diagrams for epidemiologic research. Epidemiology 10, 37-48.

25. Pearl J (1995) Causal diagrams for empirical research. Biometrika 82, 669-710.

26. Morales-Ruán MDC, Méndez-Gómez Humarán I, Shamah-Levy T et al. (2014) Food insecurity is associated with obesity in adult women of Mexico. Salud Publica Mex 56, Suppl. 1, S54-S61.

27. Chun I-A, Ryu S-Y, Park J et al. (2015) Associations between food insecurity and healthy behaviors among Korean adults. Nutr Res Pract 9, 425-432.

28. Rezazadeh A, Omidvar N, Eini-Zinab H et al. (2016) Food insecurity, socio-economic factors and weight status in two Iranian ethnic groups. Ethn Health 21, 233-250.

29. Isanaka S, Mora-Plazas M, Lopez-Arana S et al. (2007) Food insecurity is highly prevalent and predicts underweight but not overweight in adults and school children from Bogotá, Colombia. J Nutr 137, 2747-2755.

30. Darmon N \& Drewnowski A (2008) Does social class predict diet quality? Am J Clin Nutr 87, 1107-1117.

31. Drewnowski A \& Darmon N (2005) Food choices and diet costs: an economic analysis. J Nutr 135, 900-904.

32. Ledikwe JH, Blanck HM, Khan LK et al. (2006) Low-energydensity diets are associated with high diet quality in adults in the United States. J Am Diet Assoc 106, 1172-1180.

33. Larson NI, Story MT \& Nelson MC (2009) Neighborhood environments: disparities in access to healthy foods in the US. Am J Prev Med 36, 74-81.
34. US Department of Agriculture (2009) Access to Affordable and Nutritious Food: Measuring and Understanding Food Deserts and Their Consequences: Report to Congress. Washington, DC: US Department of Agriculture, Economic Research Service.

35. Zhang YT, Laraia BA, Mujahid MS et al. (2016) Is a reduction in distance to nearest supermarket associated with BMI change among type 2 diabetes patients? Health Place $\mathbf{4 0}$, $15-20$.

36. Cummins S, Flint E \& Matthews SA (2014) New neighborhood grocery store increased awareness of food access but did not alter dietary habits or obesity. Health Aff (Millwood) 33, 283-291.

37. Cummins S (2005) Large scale food retailing as an intervention for diet and health: quasi-experimental evaluation of a natural experiment. J Epidemiol Community Health 59, $1035-1040$.

38. Zimmerman FJ (2011) Using marketing muscle to sell fat: the rise of obesity in the modern economy. Annu Rev Public Health 32, 285-306.

39. Oldroyd J, Burns C, Lucas P et al. (2008) The effectiveness of nutrition interventions on dietary outcomes by relative social disadvantage: a systematic review. J Epidemiol Community Health 62, 573-579.

40. Neuhouser ML, Thompson B, Coronado GD et al. (2004) Higher fat intake and lower fruit and vegetables intakes are associated with greater acculturation among Mexicans living in Washington State. J Am Diet Assoc 104, 51-57.

41. Yang EJ, Chung HK, Kim WY et al. (2007) Chronic diseases and dietary changes in relation to Korean Americans' length of residence in the United States. J Am Diet Assoc 107, 942-950.

42. Szanton SL, Gill JM \& Allen JK (2005) Allostatic load: a mechanism of socioeconomic health disparities? Biol Res Nurs 7, 7-15.

43. Fowler-Brown AG, Bennett GG, Goodman MS et al. (2009) Psychosocial stress and 13-year BMI change among blacks: the Pitt County Study. Obesity (Silver Spring) 17, 2106-2109.

44. Epel ES, McEwen B, Seeman T et al. (2000) Stress and body shape: stress-induced cortisol secretion is consistently greater among women with central fat. Psychosom Med 62, 623-632.

45. Adler NE \& Rehkopf DH (2008) US disparities in health: descriptions, causes, and mechanisms. Annu Rev Public Health 29, 235-252.

46. Sher L \& Vilens A (editors) (2010) Immigration and Mental Health: Stress, Psychiatric Disorders, and Suicidal Behavior Among Immigrants and Refugees. Hauppauge, NY: Nova Science.

47. Levitt MJ, Lane JD \& Levitt J (2005) Immigration stress, social support, and adjustment in the first postmigration year: an intergenerational analysis. Res Hum Dev 2, 159-177.

48. Gee GC (2008) A multilevel analysis of the relationship between institutional and individual racial discrimination and health status. Am J Public Health 98, 9 Suppl., S48-S56.

49. Hattar-Pollara M \& Meleis AI (1995) The stress of immigration and the daily lived experiences of Jordanian immigrant women in the United States. West J Nurs Res 17, 521-539.

50. McAdams MA, Van Dam RM \& Hu FB (2007) Comparison of self-reported and measured BMI as correlates of disease markers in US adults. Obesity (Silver Spring) 15, 188-188.

51. Gillum RF \& Sempos CT (2005) Ethnic variation in validity of classification of overweight and obesity using self-reported weight and height in American women and men: the Third National Health and Nutrition Examination Survey. Nutr J 4, 27. 